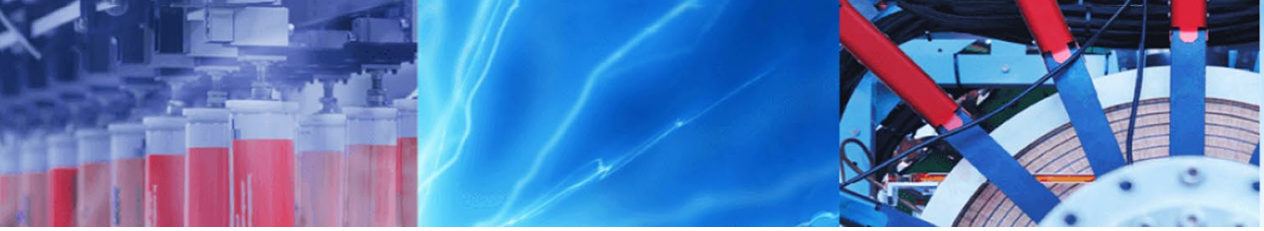

Research Article

\title{
Extraction and determination of Th(IV) from aqueous acidic solutions using natural cassitrite adsorbent
}

\author{
Hany Lotfy Weheish ${ }^{1}$. Abdou Ali Abdou ${ }^{1}$. Wagiha Hamed Mahmoud ${ }^{2}$. Sherien Hussien Ahmed ${ }^{1}$. \\ Ahmed Hussien Orabi ${ }^{1}$
}

(c) Springer Nature Switzerland AG 2019

\begin{abstract}
This work concerned with the extraction of Th(IV) from aqueous solutions using natural cassitrite adsorbent natural tin oxide mineral $\left(\mathrm{SnO}_{2}\right)$. The achieved maximum Th(IV) adsorption efficiency (99.2\%) depends mainly on some effective parameters such as $\mathrm{pH}$ value, contact time, dose of cassiterite, concentration of Th(IV) and temperature. The Langmuir and Freundlich models are used to simulate the sorption isotherms, respectively. On the other hand, not less than $99.6 \%$ of the uptaken Th(IV) was regenerated using $0.005 \mathrm{~mol} \mathrm{~L}^{-1} \mathrm{HCl}$ solution by stirring for $25 \mathrm{~min}$ to yeild Th(IV) concentrated solution. The concentrations of Th(IV) in all extraction process were spectrophotometric estimated using 1,4-di-hydroxy anthraquinone and Arsenazo(III) at $\lambda_{\max } 600$ and $655 \mathrm{~nm}$, respectively.
\end{abstract}

Keywords Thorium $\cdot 1,4-$ Di-hydroxy anthraquinone $\cdot$ Cassiterite

\section{Introduction}

Tin presently find extensive uses in industrial and domestic applications. It has been used extensively for soldering, corrosion prevention and food packaging. Tin is found in Egypt as cassiterite mineral and the main tin bearing deposits occur in the central part of the Eastern Desert of Egypt [1] There are many industrial techniques for tin extraction from its ores depending on the type of the ore itself, oxide or sulfide. Each type of the ore should be treated by the suitable technique according to its chemical composition [2]. Tin is extracted from oxide ores usually by reduction smelting of the ore at high temperature $\left(1200^{\circ} \mathrm{C}\right)$ using suitable fluxing agent silica or lime depending on the type and quality of the gangue material present in the ore [3].

Direct determination of uranium and thorium is still difficult because of insufficient sensitivity, lack of selectivity, presence of complex matrix, and poor precision and accuracy. To solve these problems, pre-concentration and separation techniques have been used for uranium and thorium determination in environmental and biological samples. Online separation and pre-concentration of thorium and uranium is carried out by means of uranium and tetravalent actinides resin. After elution, Th(IV) and $\mathrm{U}(\mathrm{VI})$ are spectrophotometric detected after reaction with Arsenazo-III in different types of environmental sample matrices achieving high selectivity levels [4].

New surface ion-imprinted composite polymer was used for the extracting and pre-concentrating traces of Th(IV) ion prior to its photometric determination. The maximum uptake capacity of this material and that of the non-imprinted polymer at $\mathrm{pH} 4.5$ are 56.8 and $26.3 \mathrm{mg} \mathrm{g}^{-1}$, respectively. Recovery exceeds $95 \%$ and is complete within $5 \mathrm{~min}$. The relative standard deviation is $<2.5 \%$, the detection limit is $0.54 \mu \mathrm{g} \mathrm{L}^{-1}(3 \sigma)$. The imprinted polymer was coupled to spectrophotometry to separate and determine trace levels of Th(IV) in a soil standard material with satisfactory results [5]. More over different biomaterials of high Th(IV) sorption efficiency such as rice bran (RB) and wheat

$\triangle$ Abdou Ali Abdou, abdouchem76@gmail.com| ${ }^{1}$ Nuclear Materials Authority, P.O. Box 530, El-Maadi, Cairo, Egypt. ${ }^{2}$ Chemistry Department, Faculty of Science, Ain Shams University, Cairo, Egypt.

SN Applied Sciences (2019) 1:1395 | https://doi.org/10.1007/s42452-019-1481-5

Received: 8 August 2019 / Accepted: 10 October 2019 / Published online: 14 October 2019 
bran (WB) in the strong acidic media. These sorbents have the sorption capacities 49.3 and $38.7 \mathrm{mg} \mathrm{g}^{-1}$ for RB and WB respectively from distribution isotherms in $4 \mathrm{~mol} \mathrm{~L}^{-1} \mathrm{HNO}_{3}$.

The mentioned biomaterials were already applied for the extraction of thorium from a real sample (monazite mineral) with achieved extraction efficiencies of 95.4 and $74.6 \%$ from $4 \mathrm{~mol} \mathrm{~L}^{-1}$ nitric acid for $\mathrm{RB}$ and $\mathrm{WB}$, respectively. The selected bio-sorbents have the potential to be applied on industrial scale because of economic and operational benefits. Tin dioxide belongs to the family of the equivalent element oxides $\mathrm{AO}_{2}\left(\mathrm{SiO}_{2}, \mathrm{MnO}_{2}, \mathrm{TiO}_{2}, \mathrm{SnO}_{2}\right)$. These hydrous oxides show acidic and ion exchange properties due to Bronsted acidic groups. They behave either as cationic or anionic exchangers, depending upon the basicity of the central atom and the strength of the $\mathrm{M}-\mathrm{O}$ bond relative to that of the $\mathrm{O}-\mathrm{H}$ bond in the hydroxyl group, if the hydroxyl groups are the only Bronsted acidic groups present [6]. The equilibrium may be written as follows: different adsorption properties to both anions and cations. The $a$-(or ortho) form is usually prepared by the low temperature hydrolysis of Sn(IV) salts in aqueous solution and is readily soluble in both acids and bases. On the other hand, the $\beta$-(or meta) form which is generally produced by the action of hot nitric acid on the tin metal, or by the high temperature hydrolysis of Sn(IV) salts is very much more stable [7].

In this context, the objective of the present paper is using the Egyptian natural cassiterite mineral for separating Th(IV) from both aqueous synthetic solutions and ore materials aqueous solutions. The extracted Th(IV) was spectrophotometric determined using 1,4-dihydroxy anthraquinone and Arsenazo(III) at $\lambda_{\max } 600$ and $655 \mathrm{~nm}$, respectively.

$\underset{\mathrm{Sn}}{ } \underset{\mathrm{O}}{\mathrm{OH}_{2}} \underset{\mathrm{H}^{+}}{\rightleftharpoons} \frac{\searrow}{\gamma} \mathrm{Sn}-\mathrm{OH} \underset{\mathrm{OH}^{-}}{\rightleftharpoons} \stackrel{\searrow}{\rightleftharpoons} \mathrm{Sn}-\mathrm{O}^{-}+\mathrm{H}_{2} \mathrm{O}$

The acidity scale of these different oxides is established by comparison of the $\mathrm{pH}$ of the isoelectric points. We notice that the acidic strength decreases in the order $\mathrm{SiO}_{2}, \mathrm{MnO}_{2}$, $\mathrm{TiO}_{2}, \mathrm{SnO}_{2}$ and so do the capacities for cationic exchangers in the basic media. The values of the $\mathrm{pH}$ of the isoelectric points depend on the structures of the oxides.

The divalent transition elements are easily retained in acidic media although these oxides are anionic exchangers in such media; these elements are hydrolysable and have a great affinity for the oxygen atoms of the hydroxyl groups. The ion-exchange reaction may be represented:

\section{Experimental}

\subsection{Materials}

\subsubsection{Standard Th(IV) solution}

A stock solution of $500 \mu \mathrm{g} \mathrm{mL}^{-1}$ of thorium was prepared by accurately weighing $0.256 \mathrm{~g}$ of thorium nitrate tetrahydrate, $\left[\mathrm{Th}\left(\mathrm{NO}_{3}\right)_{4} \cdot 4 \mathrm{H}_{2} \mathrm{O}\right]$ dissolved in approximately $30 \mathrm{~mL}$ of double-distilled water and adjusted to $\mathrm{pH} 2.7$ using dilute hydrochloric acid and closed up to $250 \mathrm{~mL}$

$$
\left(\varlimsup_{\gamma} \mathrm{Sn}-\mathrm{OH}\right)_{m}+\mathrm{M}^{4+} \rightleftharpoons\left[\left(\bigvee_{/} \mathrm{Sn}-\mathrm{O}\right)_{m} \mathrm{M}\right]^{(4-m)^{+}}{ }^{+} m \mathbf{H}^{+}
$$

The ion-exchange reaction may be represented as follows:

$\mathrm{M}_{\mathrm{aq}}^{4+}+\alpha \mathrm{H}_{\mathrm{SnO}_{2}}^{+} \leftrightarrow \alpha \mathrm{H}_{\mathrm{aq}}^{+}+\mathrm{M}_{\mathrm{SnO}_{2}}^{4+}$

According to our results, the equilibrium for retention of $\mathrm{M}^{4+}$ may be written:

$\searrow_{\mathrm{Sn}} \longrightarrow \mathbf{O H}+\mathbf{M}^{4+} \rightleftharpoons\left[\searrow_{\mathrm{Sn}}-\mathbf{O}-\mathbf{M}\right]^{+}+\mathbf{H}^{+}$

Frankly, hydrous Sn(IV) oxide used for separating Th(IV) exists in at least two distinct forms, often referred to as the $\alpha$ - and $\beta$-stannic acids and these exhibit in a volumetric measuring flask using double-distilled water. Solutions of lower concentrations were obtained via dilution process.

\subsubsection{Preparation of cassiterite adsorbent}

A weight $10 \mathrm{~g}$ of Egyptian cassiterite collected from Rasheid factory of black sand was ground to $0.297 \mathrm{~mm}$ and treated with $100 \mathrm{~mL}$ of $3 \mathrm{~mol} \mathrm{~L}^{-1}$ hydrochloric acid and stirred for $48 \mathrm{~h}$ at $100-110^{\circ} \mathrm{C}$ in atmospheric conditions. After filtration, the cassiterite residue left over the filter paper was washed carefully several times with distilled 
Table 1 Complete chemical analysis of the cassiterite

\begin{tabular}{lr}
\hline Oxides & Wt\% \\
\hline $\mathrm{SnO}_{2}$ & 97.70 \\
$\mathrm{Ta}_{2} \mathrm{O}_{5}$ & 0.95 \\
$\mathrm{Nb}_{2} \mathrm{O}_{5}$ & 0.39 \\
$\mathrm{Fe}_{2} \mathrm{O}_{3}$ & 0.34 \\
$\mathrm{TiO}_{2}$ & 0.40 \\
$\mathrm{SiO}_{2}$ & 0.10 \\
Total & 99.88 \\
\hline
\end{tabular}

water to remove any traces of chloride impurities and then dried at $100^{\circ} \mathrm{C}$ for $2 \mathrm{~h}$ [8]. The chemical analysis of the purified cassiterite represents in Table 1 according to Abdel-Aal and Abdel-Hay [9].

\section{Results and discussion}

\subsection{Structure characterization of cassiterite}

The morphology structure of natural cassiterite sorbent was studied using scanning electron microscope (SEM) analysis. While the crystal structure of was characterized by X-ray diffraction (XRD) analysis. Infrared (FT-IR) analysis was used to confirm the present functional groups.

\subsubsection{SEM analysis}

Figure 1 represented SEM analysis of both natural (a) and purified cassitrite (b).This figure proved the necessary matter for purification of the natural cassiterite to be useful for application in the extraction process of Th(IV) from aqueous solutions. Chemical composition of natural cassiterite prior to the removal of impurities represented in Table 1

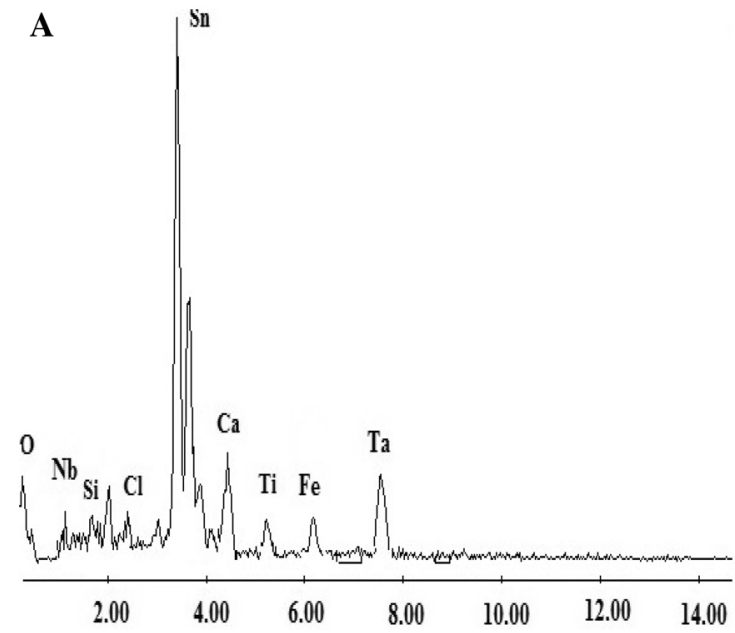

was found agreement with the mineralogy study of natural cassiterite which contains some associated minerals. The analyzed cassiterite especially after purification process have more than $97 \mathrm{wt} \%$ of $\mathrm{SnO}_{2}$, [9].

\subsubsection{XRD analysis}

From the XRD pattern, the observed diffraction intense peaks at (39.9), (51.33), (57.81), (80.94), (86.25), and (99.7) ${ }^{\circ} 2$ theta. Figure 2 shows the XRD pattern of the $\mathrm{SnO}_{2}$ cassitrite mineral. Using the Debye-Scherrer equation [10], the mean crystallite size of the adsorbent was estimated as follows:

$D=\frac{0.9 \lambda}{\beta \cos \theta}$

where $\lambda, \beta, \theta$ are the $X$-ray wavelength of radiation used. The XRD pattern of the adsorbent showed strong peaks of the cassiterite phase of $\mathrm{SnO}_{2}$ along with some weak traces of metastable orthorhombic phase. X-ray diffraction revealed that the crystalline structure significantly.

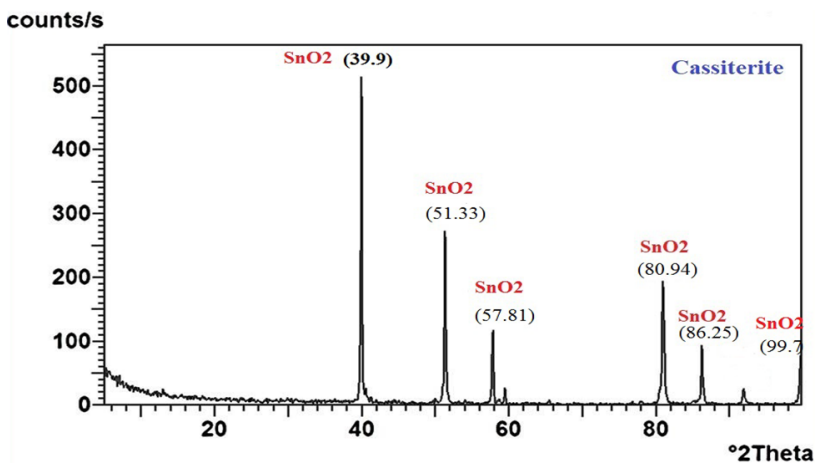

Fig. 2 XRD pattern of the cassiterite mineral $\left(\mathrm{SnO}_{2}\right)$

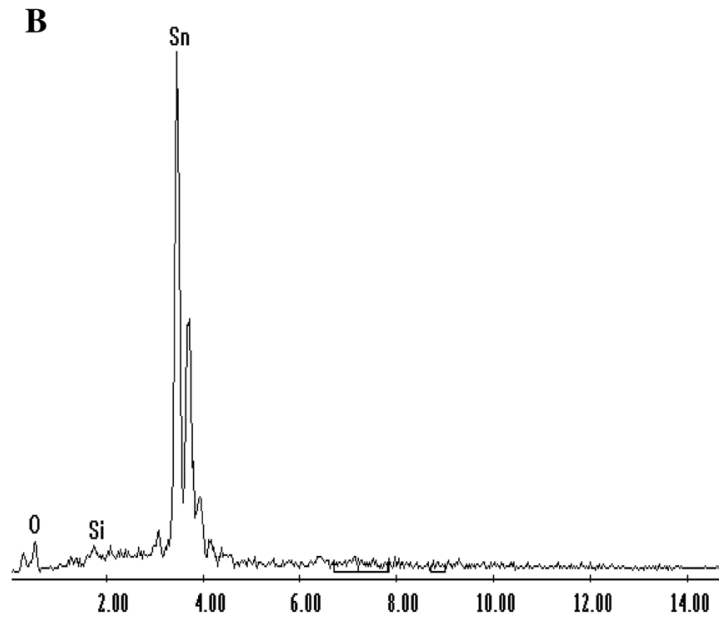

Fig. 1 ESEM analysis of cassiterite before (a) and after (b) purification 


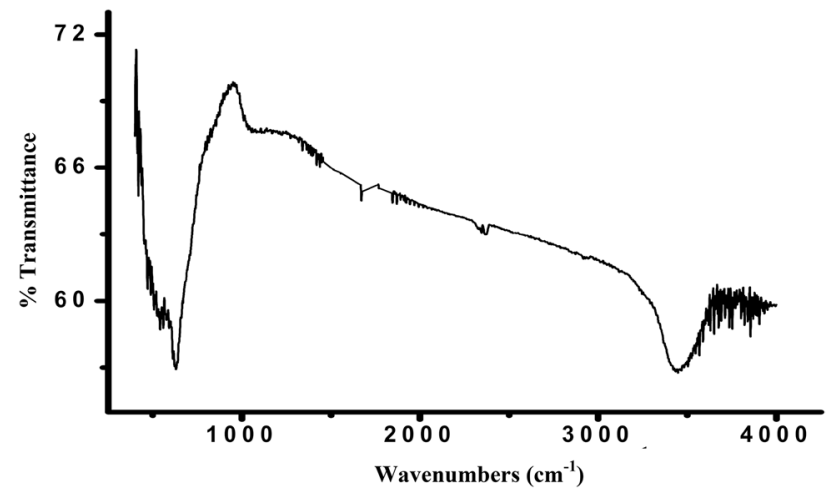

Fig. 3 Infrared spectra of cassiterite mineral

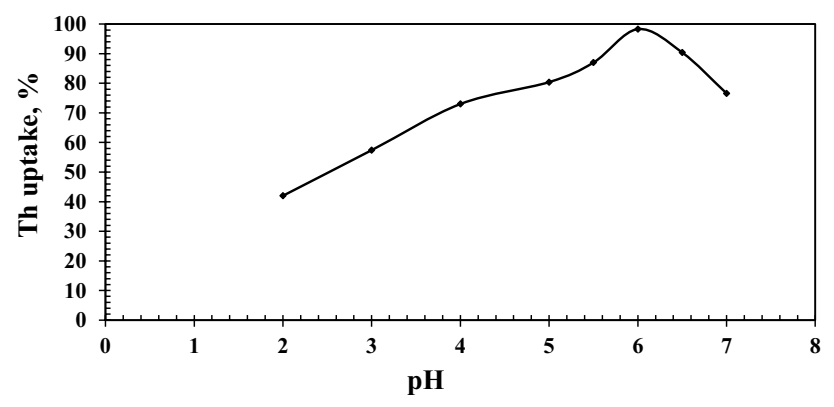

Fig. 4 Effect of $\mathrm{pH}$ on the Th(IV) uptake

\subsubsection{FT-IR analysis}

From the FT-IR spectra, Fig. 3 there are two broad bands at 3445 and $1645 \mathrm{~cm}^{-1}$ attributed to the $\mathrm{O}-\mathrm{H}$ stretching vibration of water absorbed by the sample. The strong peak at $552 \mathrm{~cm}^{-1}$ agrees with the stretching vibrations of the $\mathrm{Sn}-\mathrm{OH}$ bonds, while the peak at $632 \mathrm{~cm}^{-1}$ region assigned to the stretching modes of the $\mathrm{Sn}-\mathrm{O}-\mathrm{Sn}$. The presence of these strong bands proved the hydration process of the natural $\mathrm{SnO}_{2}$ as has been mentioned in Eq. (1) [6].

\subsection{Optimization of Th(IV) adsorption}

To optimize the Th(IV) adsorption process several effective parameters were studied including: $\mathrm{pH}$ value, the contact time, adsorbent dose, volume aqueous solution and the initial Th(IV) concentration.

\subsubsection{Effect of $\mathrm{pH}$ on the Th(IV) uptake}

Data, Fig. 4 represented the effect of changing $\mathrm{pH}$ values of the prepared Th(IV) solution from $\mathrm{pH} 2$ to $\mathrm{pH} 7$ upon Th(IV) adsorption efficiencies by mixing $0.25 \mathrm{~g}$ of cassiterite with $50 \mathrm{~mL}$ of Th(IV) solution assaying $50 \mu \mathrm{g} \mathrm{mL}^{-1}$

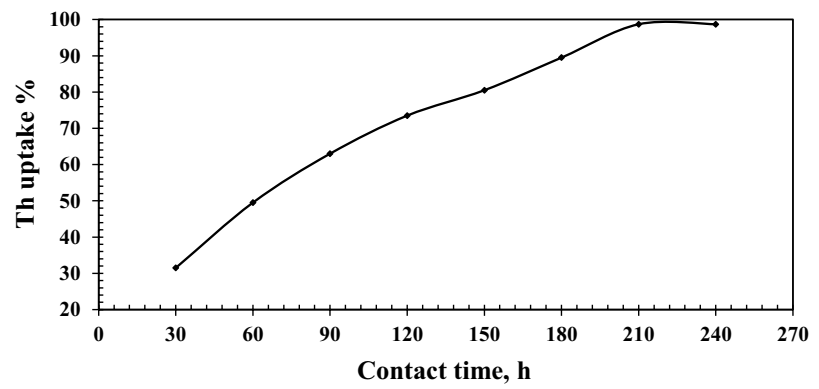

Fig. 5 Effect of contact time on the Th(IV) uptake

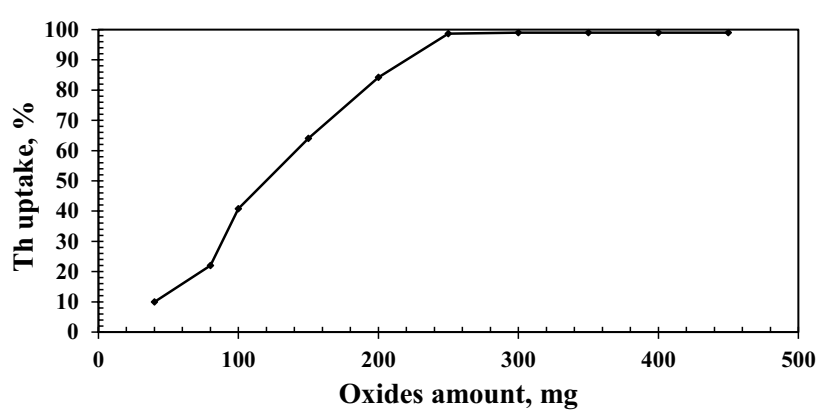

Fig. 6 Effect of adsorbents dose on the Th(IV) uptake

and shaking for $4 \mathrm{~h}$ at room temperature. The filtrates were analyzed for determining the percent uptake. It was noticed that, Th(IV) adsorption efficiency increased gradually up to $98.3 \%$ at the $\mathrm{pH} 6$ and decreased gradually up to $76.6 \%$ at $\mathrm{pH}$ 7. From the adsorption mechanism Eq. (2), the presence of many $\mathrm{OH}$ groups at $\mathrm{pH} 6$ led to encourage the adsorption process [6]. So, the suitable choice for the maximum adsorption efficiency of Th(IV) was pH 6.

\subsubsection{Effect of contact time}

To find out the optimum time required for the maximum adsorption of Th(IV) using cassiterite adsorbent, a weight $0.25 \mathrm{~g}$ of the adsorbent was mixed with $50 \mathrm{~mL}$ of Th(IV) solution assaying $50 \mu \mathrm{g} \mathrm{mL}^{-1}$ adjusted to $\mathrm{pH} 6$ and shaking for different time intervals between 30 and $240 \mathrm{~min}$. The filtrates were analyzed for determining the percent uptake for each shaking period. The obtained results, Fig. 5 revealed that the contact time of $210 \mathrm{~min}$ is found sufficient for the maximum uptake of Th(IV) not less than $98.7 \%$.

\subsubsection{Effect of adsorbents dose}

This parameter was studied with different doses of cassiterite ranged from 0.04 to $0.4 \mathrm{~g}$ at the obtained optimal conditions. The obtained results, Fig. 6 proved that Th(IV) 


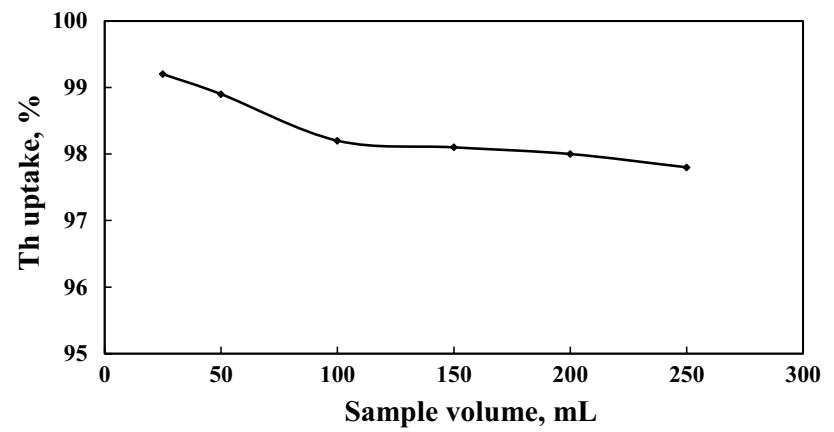

Fig. 7 Effect of volume aqueous solution on the Th(IV) uptake

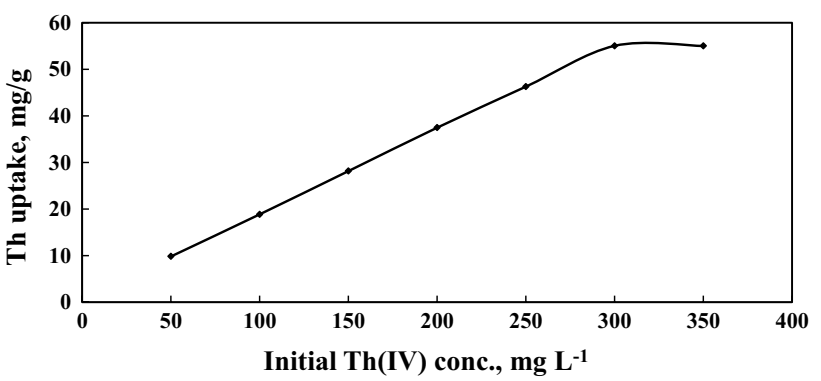

Fig. 8 Effect of initial concentration on the Th(IV) uptake

uptaken efficiency increased gradually from 10 to $99 \%$ with increasing the adsorbent dose from 0.04 to $0.3 \mathrm{~g}$, due to high surface area and sufficient active sites for Th(IV) adsorption.

\subsubsection{Effect of volume aqueous solution}

To find out the effect of sample volume on uptake of $\mathrm{Th}$ (IV), solutions containing $50 \mu \mathrm{g} \mathrm{mL}^{-1}$ of Th(IV) (keeping the total amount of loaded metal ion constant) present in varying the volume form 25 to $250 \mathrm{~mL}$ of the aqueous solution was carried out by adjusting the $\mathrm{pH}$ to 6.0 and mixed with $0.3 \mathrm{~g}$ of adsorbents after $210 \mathrm{~min}$. The obtained results, Fig. 7 revealed that Th(IV) uptaken efficiency decreased gradually from 99.2 to $97.8 \%$ with increasing the volume aqueous solution.

\subsubsection{Effect of initial Th(IV) concentration}

This factor was studied using a sample volume $(50 \mathrm{~mL})$ of standard Th(IV) solution assaying different concentrations ranged from 50 to $350 \mu \mathrm{g} \mathrm{m}^{-1}$ of Th(IV) under the optimum conditions previously studied. Results, Fig. 8 reflected that the maximum Th(IV) adsorption capacity increased up to $99.2 \%$ when Th(IV) concentration increased up to $300 \mu \mathrm{g} \mathrm{m}^{-1}$ and then remains relatively constant.

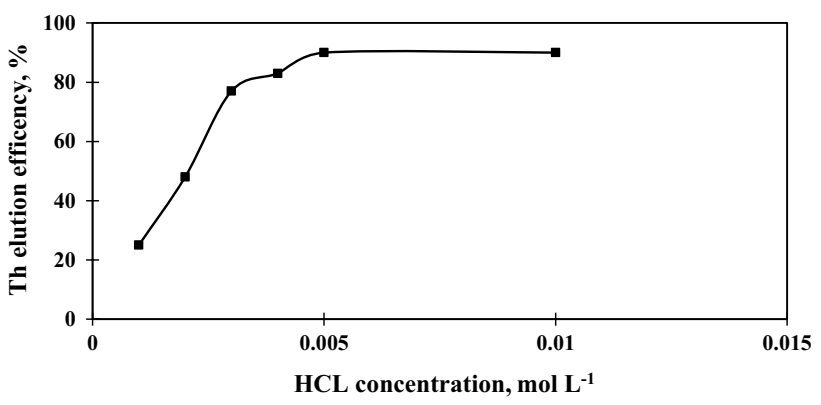

Fig. 9 Effect of eluent concentration on the Th(IV) recovery

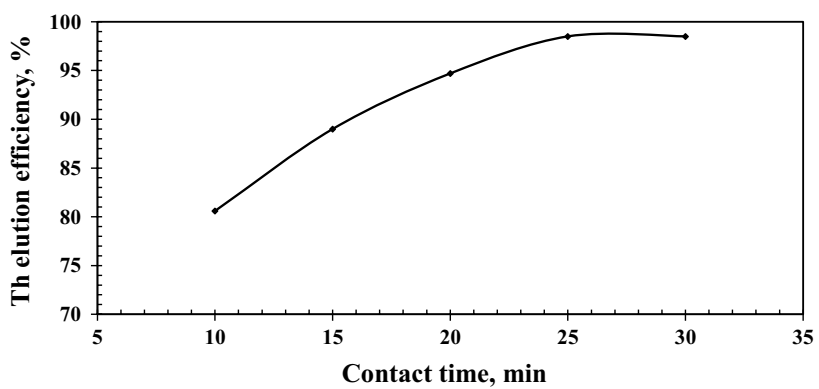

Fig. 10 Effect of contact time on the Th(IV) recovery

\subsection{Optimization of Th(IV) elution process}

Elution process is not only used to regenerate the loaded adsorbent, but also to have a concentrated aqueous solution suitable for determination of Th(IV). Several effective parameters were studied to optimize the elution process using $\mathrm{HCl}$ solution such as, concentration, contact time, eluent volume $(\mathrm{S} / \mathrm{L})$ ratio.

\subsubsection{Effect of eluent concentration}

This factor was already studied by mixing $0.3 \mathrm{~g}$ of the full saturated adsorbent with $25 \mathrm{~mL}$ of $\mathrm{HCl}$ solution of different concentrations varying between 0.0002 and $0.003 \mathrm{~mol} \mathrm{~L}^{-1}$ and stirred for $15 \mathrm{~min}$. After filtration and analysis, the obtained data, Fig. 9 emphasized that the best Th(IV) elution efficiency of $90 \%$ was found at $\mathrm{HCl}$ concentration of $0.005 \mathrm{~mol} \mathrm{~L}^{-1}$ compared to the others. Elution process of the loaded cassiterite required the utilizing of dilute acid solution to avoid the free anion interfering in Th(IV) determination method.

\subsubsection{Effect of contact time}

Figure 10 represented the obtained data of varying the contact time periods from 10 to $30 \mathrm{~min}$ up on Th(IV) elution efficiency from the loaded cassiterite adsorbent by 
mixing $0.3 \mathrm{~g}$ with $25 \mathrm{~mL}$ of $0.005 \mathrm{~mol} \mathrm{~L}^{-1} \mathrm{HCl}$ solution. It was observed that increasing the contact time has a remarkable effect on Th(IV) elution efficiency which achieved the maximum value (98.5\%) at $25 \mathrm{~min}$.

\subsubsection{Effect of eluent volume (S/L) ratio}

It is known that, minimum eluent volume is necessary to obtain higher pre-concentration factors. So, different volumes of $0.005 \mathrm{~mol} \mathrm{~L}^{-1} \mathrm{HCl}$ solution ranged from 5 to $40 \mathrm{~mL}$ were mixed with $0.3 \mathrm{~g}$ of the full saturated adsorbent and stirred for $25 \mathrm{~min}$. It was shown in Fig. 11 that the best Th(IV) elution efficiency of $99.6 \%$ achieved using $35 \mathrm{~mL}$ of eluent solution by stirring for $25 \mathrm{~min}$.

Finally, it can be concluded from this study that, at least $99.6 \%$ of Th(IV) could be regenerated from the loaded cassiterite using $35 \mathrm{~mL}$ of $0.005 \mathrm{~mol} \mathrm{~L}^{-1} \mathrm{HCl}$ solution by stirring for $25 \mathrm{~min}$.

\subsection{Effect of diverse ions}

The interfering effect of various ions at mg levels on Th(IV) determination via the proposed method was examined. The results, Table 2 reflected that, the high concentrations of alkali elements e.g. $\mathrm{Na}, \mathrm{K}, \mathrm{Ca}$ and $\mathrm{Mg}$ and moderate concentrations of some transition elements e.g. Fe, V, Cu has very limit effect on Th(IV) determination while low concentrations of $\mathrm{Zr}, \mathrm{Hf}$ and $\mathrm{Ti}$ ions led to more than $\pm 2.0 \%$ error.

\subsection{Equilibrium, kinetic and thermodynamic studies}

\subsubsection{Adsorption isotherms studies}

Equilibrium data of the adsorption process is essential to develop an equation that used to compare different adsorbents under different operating conditions and to design and optimize an operating procedure. Adsorption isotherms provides rapid and concise information about adsorption process and explains the relationship between

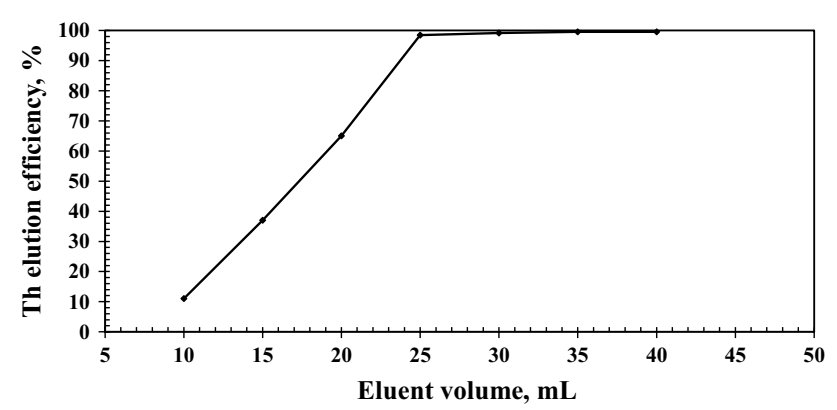

Fig. 11 Effect of eluent volume (S/L) ratio on the Th(IV) recovery
Table 2 Effect various elements on separations of Th(IV)

\begin{tabular}{lll}
\hline Interfering ion & $\begin{array}{l}\text { Amount mixture } \\
\left(\mathrm{mg} \mathrm{L}^{-1}\right)\end{array}$ & Th recovery (\%) \\
\hline $\mathrm{Na}^{+}, \mathrm{K}^{+}, \mathrm{Ca}^{2+}$ and $\mathrm{Mg}^{2+}$ & 1000 & 99.2 \\
$\mathrm{Fe}^{3+}, \mathrm{Al}^{3+}$ and $\mathrm{Co}^{3+}$ & 500 & 98.8 \\
$\mathrm{Cr}^{6+}, \mathrm{VO}^{2+}$ and $\mathrm{Cu}^{2+}$ & 300 & 98.5 \\
$\mathrm{Y}^{3+}, \mathrm{La}^{3+}$ and $\mathrm{Ce}^{3+}$ & 300 & 98.8 \\
$\mathrm{Ti}^{4+}, \mathrm{Zr}^{4+}$ and $\mathrm{Hf}^{4}$ & 100 & 98.4 \\
$\mathrm{SO}_{4}{ }^{2-}, \mathrm{Cl}^{-}$and $\mathrm{PO}_{4}{ }^{3-}$ & 300 & 99.1 \\
\hline
\end{tabular}

the amounts of species adsorbed by an adsorbent. In this work, two adsorption isotherm models were examined, namely Langmuir and Freundlich. Various concentrations of Th(IV) solution were prepared and the adsorption performance of cassitrite adsorbent was tested to investigate the adsorption isothermal equation.

Langmuir model is given as follows:

$\frac{\mathrm{C}_{\mathrm{e}}}{\mathrm{q}_{\mathrm{e}}}=\frac{\mathrm{C}_{\mathrm{e}}}{\mathrm{Q}_{\max }}+\frac{1}{\mathrm{~K}_{\mathrm{L}} \mathrm{Q}_{\max }}$

The amount of adsorption was calculated by:

$\mathrm{q}_{\mathrm{e}}=\left(\mathrm{C}_{\mathrm{i}}-\mathrm{C}_{\mathrm{e}}\right) \times \frac{\mathrm{V}}{\mathrm{M}}$

The plot of $C_{e} / q_{e}$ versus $C_{e}$ gave a straight line, Fig. 12 where the adsorption behavior follows the Langmuir adsorption isotherm. $\mathrm{Q}_{\max }$ and $\mathrm{KL}$ were calculated from the slope and intercept of linear plots.

Freundlich isotherm assumed a heterogeneous surface and an exponential distribution of the energy of the active sites. Linearized equation of Freundlich model is given as follows:

$\log q_{e}=\log K_{f}+\frac{\log C e}{n}$

The plot of $\log q_{e}$ versus $\log C_{e}$ gave a straight line, Fig. 13 so, the adsorption behavior follows the Freundlich

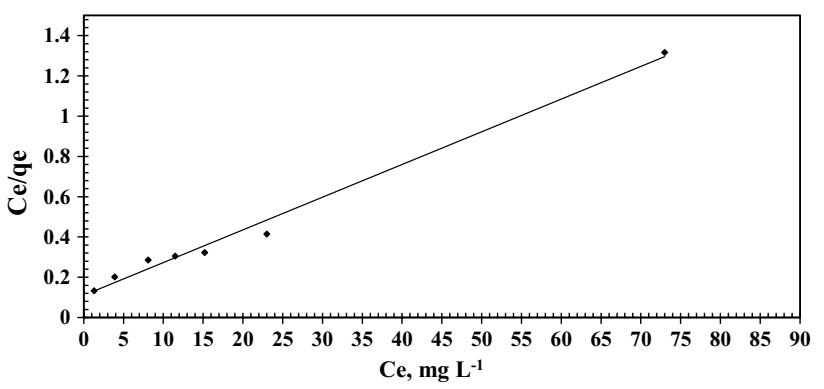

Fig. 12 Langmuir adsorption isotherm simulation of Th(IV) adsorption on cassiterite adsorbent 


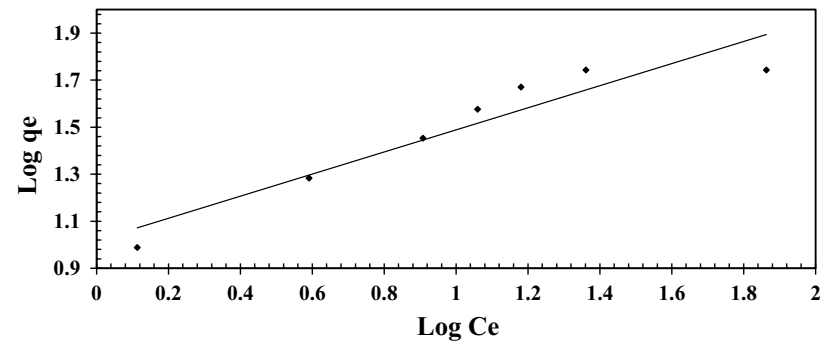

Fig. 13 Freundlich adsorption isotherm simulation of Th(IV) adsorption on cassiterite adsorbent

adsorption isotherm. $\mathrm{K}_{\mathrm{f}}$ and $\mathrm{n}$ were calculated from the slope and intercept of linear plots.

Data, Table 3 confirmed that the equilibrium is best described by a Langmuir isotherm, with correlation coefficients above 0.977. Langmuir isotherm showed a better fit than the Freundlich isotherm, and indicating the applicability of monolayer coverage of Th(IV) on cassitrite. The maximum monolayer adsorption capacities of Th(IV) on cassiterite was found to be $61.46 \mathrm{mg} \mathrm{g}^{-1}$.

\subsubsection{Uptake kinetics studies}

Adsorption rate established Th(IV) uptaken kinetics on cassiterite under various process conditions. Different kinetic models, such as pseudo first order kinetic model and pseudo second order kinetic model are used. The employed pseudo first order rate equation is given as follows:

$\log \left(q_{e}-q_{t}\right)=\log q_{e}-\frac{k_{1}}{2.303} t$

The plot of $\log \left(\mathrm{q}_{\mathrm{e}}-\mathrm{q}_{\mathrm{t}}\right)$ versus time gave a straight line, Fig. 14 shows that the adsorption behavior follows the pseudo first order. The pseudo first order rate constant $\mathrm{K}_{1}$ was calculated from the slope. The employed pseudo second order rate equation is given as follows:

$\frac{\mathrm{t}}{\mathrm{q}_{\mathrm{t}}}=\frac{1}{\mathrm{~K}_{2} \mathrm{q}_{\mathrm{e}}^{2}}+\frac{1}{\mathrm{q}_{\mathrm{e}}} \mathrm{t}$

The plot of $t / q_{t}$ versus time gave a straight line, Fig. 15 reflected that the adsorption behavior follows the pseudo

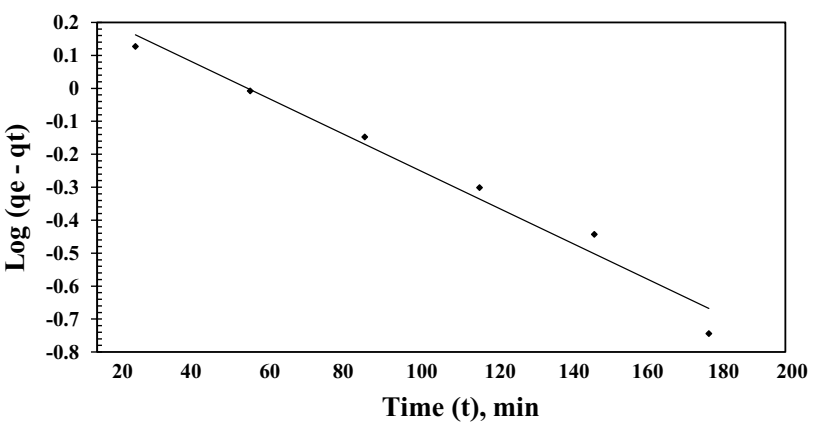

Fig. 14 Pseudo first order model rate constants for adsorption of Th(IV) ions by cassiterite

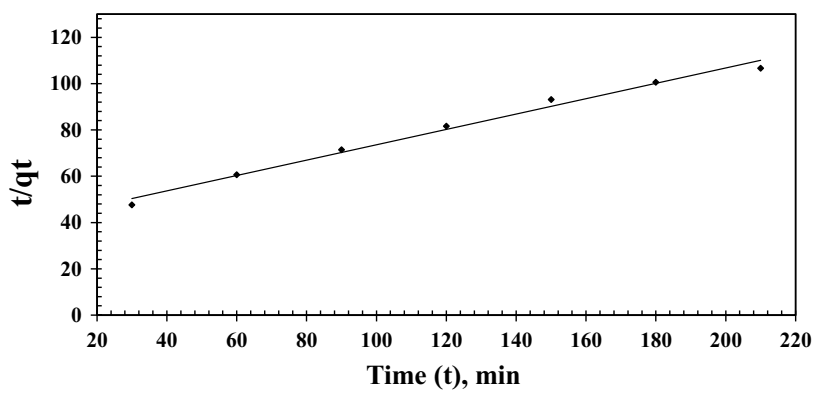

Fig. 15 Pseudo second order model rate constants for adsorption of Th(IV) ions by cassiterite

second order. The pseudo- second-order rate constant $\mathrm{K}_{2}$ was determined from the slope and intercepts.

Table 4 indicates that the adsorption of Th(IV) onto cassiterite fits well pseudo second order according correlation coefficients. For this reason, the rate limiting step may be chemical sorption or chemisorption.

\subsubsection{Thermodynamic studies}

Thermodynamic parameters such as enthalpy $\left(\Delta \mathrm{H}^{\circ}\right)$, free energy $\left(\Delta \mathrm{G}^{\circ}\right)$, and entropy $\left(\Delta \mathrm{S}^{\circ}\right)$ of adsorption were estimated using the following equations:

$\operatorname{Ln} \mathrm{K}_{\mathrm{d}}=\frac{\Delta \mathrm{S}^{\circ}}{\mathrm{R}}+\frac{-\Delta \mathrm{H}^{\circ}}{\mathrm{RT}}$

$\Delta \mathrm{G}^{\circ}=\Delta \mathrm{H}^{\circ}-\mathrm{T} \Delta \mathrm{S}^{\circ}$

Table 3 Comparison of the Langmuir and Freundlich, Parameters and correlation coefficients of isotherm models

\begin{tabular}{|c|c|c|c|c|c|c|}
\hline \multirow[t]{2}{*}{ Adsorbent } & \multicolumn{3}{|l|}{ Langmuir parameters } & \multicolumn{3}{|c|}{ Freundlich parameters } \\
\hline & Calculated $\mathrm{Q}_{\max }(\mathrm{mg} / \mathrm{g})$ & $\mathrm{K}_{\mathrm{L}}(\mathrm{L} / \mathrm{mg})$ & $\mathrm{R}^{2}$ & $\mathrm{~K}_{\mathrm{f}}(\mathrm{mg} / \mathrm{g})$ & $\mathrm{n}$ & $\mathrm{R}^{2}$ \\
\hline Cassiterite & 61.46 & 0.130 & 0.977 & 9.904 & 1.975 & 0.949 \\
\hline
\end{tabular}


Table 4 The results of pseudo first order and pseudo second order rate constants for adsorption of Th(IV) ions by cassiterite adsorbent

\begin{tabular}{llllll}
\hline Adsorbent & \multicolumn{2}{l}{$\begin{array}{l}\text { Pseudo first order } \\
\text { model }\end{array}$} & & \multicolumn{2}{l}{$\begin{array}{l}\text { Pseudo second order } \\
\text { model }\end{array}$} \\
\cline { 2 - 3 } \cline { 5 - 6 } & $\mathrm{K}_{1}\left(\mathrm{~m} \mathrm{~g}^{-1}\right)$ & $\mathrm{R}^{2}$ & & $\mathrm{~K}_{2}\left(\mathrm{mg} \mathrm{g}^{-1} \mathrm{~min}^{-1}\right)$ & $\mathrm{R}^{2}$ \\
\hline Cassiterite & 0.012 & 0.969 & 0.0028 & 0.990 \\
\hline
\end{tabular}

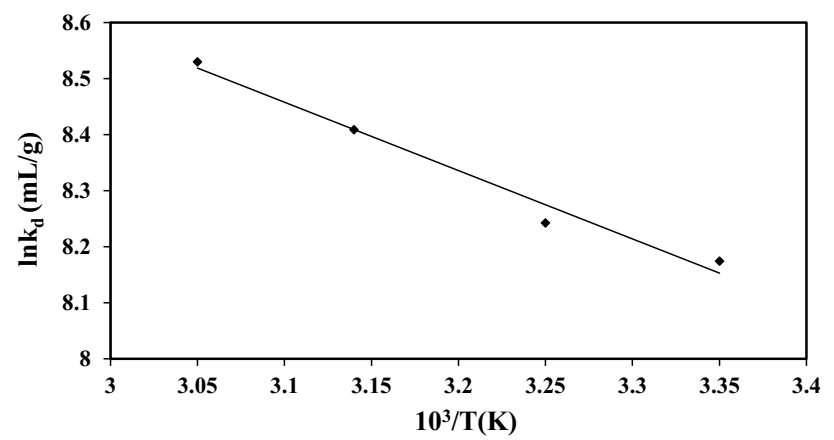

Fig. 16 Thermodynamic parameters for Th(IV) adsorption onto cassiterite

Table 5 Thermodynamic parameters for Th(IV) adsorption onto cassiterite

\begin{tabular}{llll}
\hline $\begin{array}{l}\text { Tempera- } \\
\text { ture }(\mathrm{K})\end{array}$ & $\begin{array}{l}\text { Thermodynamic parameters for thorium adsorption } \\
\text { onto cassiterite }\end{array}$ \\
\cline { 2 - 4 } & $\Delta \mathrm{H}^{\circ}(\mathrm{KJ} / \mathrm{mol})$ & $\Delta \mathrm{S}^{\circ}(\mathrm{KJ} / \mathrm{K} \mathrm{mol})$ & $\Delta \mathrm{G}^{\circ}(\mathrm{KJ} / \mathrm{mol})$ \\
\hline 298 & 9.973 & 0.101 & -20.196 \\
308 & & & -21.208 \\
318 & & & -22.220 \\
328 & & & -23.233 \\
\hline
\end{tabular}

Distribution coefficient $\left(\mathrm{K}_{\mathrm{d}}, \mathrm{mL} / \mathrm{g}\right)$ is also computed using the following equation:

$k_{d}=\frac{C_{i}-C_{e}}{C_{e}} \times \frac{v}{M}$
The values of $\Delta \mathrm{H}^{\circ}$ and $\Delta \mathrm{S}^{\circ}$ were determined from the slopes and intercepts of the plots of $\ln \mathrm{K}_{\mathrm{d}}$ versus $1 / \mathrm{T}$ by using Eq. (12), Fig. 16. Gibbs free energy $\Delta G^{\circ}$ was calculated for each working temperature by using Eq. (13).

$\mathrm{Th}$ (IV) results indicate that the adsorption process is spontaneous and endothermic dependent. The positive value of $\Delta \mathrm{S}^{\circ}$ suggests some structural changes in the adsorbate and adsorbent. The negative values for the Gibbs free energy change show that the adsorption process is thermodynamically feasible and the degree of spontaneity of the reaction increases with increasing temperature as seen in Table 5. This is indicating that the adsorption reaction is spontaneous.

\subsection{Comparison with other inorganic mineral adsorbents}

Studies on series of inorganic mineral adsorbents for $\mathrm{Th}(\mathrm{IV})$ adsorption have been widely reported in published journals recently. As some are listed in Table 6, on one hand, cassiterite is superior to some reported inorganic mineral adsorbents with shorter adsorption equilibrium time ( $210 \mathrm{~min}$ ) and higher adsorption capacity (61.46 $\mathrm{mg} \mathrm{g}^{-1}$ ) for Th(IV), whereas it usually takes hours to arrive adsorption equilibrium for other listed inorganic mineral adsorbents, and the adsorption capacity is lower. For example, $2880 \mathrm{~min}$ and $81.2 \mathrm{mg} \mathrm{g}^{-1}$ for Al-pillared rectorite [11], $300 \mathrm{~min}$ and $3.71 \mathrm{mg} \mathrm{g}^{-1}$ for Attapulgite [12], $1440 \mathrm{~min}$ and $23.2 \mathrm{mg} \mathrm{g}^{-1}$ for MX-80 bentonite [13], $2880 \mathrm{~min}$ and $38.28 \mathrm{mg} \mathrm{g}^{-1}$ for Na-bentonite [14], $90 \mathrm{~min}$ and $1.14 \mathrm{mg} \mathrm{g}^{-1}$ for Illite [15], $900 \mathrm{~min}$ and $6.55 \mathrm{mg} \mathrm{g}^{-1}$ for activated bentonite [16].

\section{Conclusion}

Cassiterite is a tin oxide natural mineral $\left(\mathrm{SnO}_{2}\right)$ used for separation of Th(IV) from either aqueous solutions. The maximum Th(IV) uptaken efficiency of $99.2 \%$ was achieved using standard Th(IV) solution assaying $50 \mu \mathrm{g} \mathrm{mL}^{-1}$ at $\mathrm{pH} 6$ using $0.3 \mathrm{~g}$ of cassiterite adsorbent by stirring for $210 \mathrm{~min}$. Applying the mentioned optimum adsorption conditions
Table 6 Comparison of adsorption capacities of cassiterite and various adsorbents for Th(IV)

\begin{tabular}{lclcc}
\hline Adsorbent & $\begin{array}{l}\text { Equilibrium time, } \\
\text { min }\end{array}$ & $\begin{array}{l}\text { Th(IV) efficiency } \\
(\%)\end{array}$ & $\begin{array}{l}\text { Adsorption capacity, q } \\
\left(\mathrm{mg} \mathrm{g}^{-1}\right)\end{array}$ & References \\
\hline Al-pillared rectorite & 2880 & 99 & 81.2 & {$[11]$} \\
Attapulgite & 300 & 100 & 3.71 & {$[12]$} \\
MX-80 bentonite & 1440 & 95 & 23.2 & {$[13]$} \\
Na-bentonite & 2880 & 90 & 38.28 & {$[14]$} \\
Illite & 90 & 85 & 1.14 & {$[15]$} \\
Activated bentonite & 900 & 100 & 6.55 & {$[16]$} \\
Cassiterite & 210 & 99.2 & 61.46 & This work \\
\hline
\end{tabular}


on $1 \mathrm{~g}$ of cassiterite adsorbent and using different Th(IV) concentrations, it can be easily calculated the maximum Th(IV) adsorption capacity of natural cassiterite adsorbent which achieved $61.46 \mathrm{mg} \mathrm{g}^{-1}$. Not less than $99.6 \%$ of Th(IV) could be regenerated from the loaded cassiterite using $35 \mathrm{~mL}$ of $0.005 \mathrm{~mol} \mathrm{~L}^{-1} \mathrm{HCl}$ solution by stirring for $25 \mathrm{~min}$. The extracted Th(IV) was determined using 1,4-di-hydroxy anthraquinone and Arsenazo(III) at $\lambda_{\max } 600$ and $655 \mathrm{~nm}$, respectively.

\section{Compliance with ethical standards}

Conflict of interest On behalf of all authors, the corresponding author states that there is no conflict of interest.

\section{References}

1. Sabet AH (1973) Tin-Tungsten mineralization in the Central Eastern Desert of Egypt. Ann Geol Surv Egypt 3:75-86

2. Habashi $F$ (1997) Handbook of extractive metallurgy, vol 2. Wiley, New York, pp 683-714

3. Murach NN, Sevryukov NN (1964) Metallurgiya olova (Metallurgy of Tin). Metallurgiya, Moscow

4. Avivar J, Ferrer L, Casas M, Cerdà V (2011) Smart thorium and uranium determination exploiting renewable solid-phase extraction applied to environmental samples in a wide concentration range. Anal Bioanal Chem 400:3585-3594. https:// doi.org/10.1007/s00216-011-5005-4

5. Cheng Z, Wang H, Wang $Y, H e F$, Zhang H, Yang S (2011) Synthesis and characterization of an ion-imprinted polymer for selective solid phase extraction of thorium(IV). Microchim Acta 173:423431. https://doi.org/10.1007/s00604-011-0576-5

6. Monji AB, Ghoulipour V, Mallah MH, Mianji BM (2015) Selective sorption of thorium (IV) from highly acidic aqueous solutions by rice and wheat bran. J Radioanal Nucl Chem 303(1):949-958. https://doi.org/10.1007/s10967-014-3559-2
7. Waters SL, Horlock PL, Kensett MJ (1983) The application of hydrous tin(IV) oxide in radiochemical separations and in particular, for the $68 \mathrm{Ge} / 68 \mathrm{Ga}$ and $82 \mathrm{Sr} / 82 \mathrm{Rb}$ generator systems. Int J Appl Radiat Isot 14(1):1023

8. Firdiyono F, Andriyah L, Ainiz FN, Arini T, Lalasari LH (2018) Preliminary study on the dissolutions of $\mathrm{Ce}, \mathrm{Nd}, \mathrm{Y}$ and $\mathrm{La}$ from mineral cassiterite by acid and alkaline leaching. Mater Sci Eng 333(1):1-7. https://doi.org/10.1088/1757-899X/333/1/012040

9. Abdel-Aal MA, Abdel-Hay ME (2012) Mineralogy and chemical distribution study of placer cassiterite and some associated new recorded minerals, east Rosetta, Egypt. Arab J Geosci 5(4):807816. https://doi.org/10.1007/s12517-011-0282-y

10. Tazikeh S, Akbari A, Talebi A, Talebi E (2014) Synthesis and characterization of tin oxide nanoparticles via the Co-precipitation method. Mater Sci Pol. https://doi.org/10.2478/s1353 6-013-0164-y

11. Yu SM, Chen CL, Chang PP, Wang TT, Lu SS, Wang XK (2008) Adsorption of Th(IV) onto Al-pillared rectorite: effect of $\mathrm{pH}$, ionic strength, temperature, soil humic acid and fulvic acid. Appl Clay Sci 38:219-226. https://doi.org/10.1016/j.clay.2007.03.008

12. Chen L, Gao X (2009) Thermodynamic study of Th(IV) sorption on attapulgite. Appl Radiat Isot 67:1-6. https://doi.org/10.1016/j. apradiso.2008.05.014

13. Lu S, Guo Z, Zhang C, Zhang S (2011) Sorption of Th(IV) on $\mathrm{MX}-80$ bentonite: effect of $\mathrm{pH}$ and modeling. J Radioanal Nucl Chem 287:621-628. https://doi.org/10.1007/s10967-010-0810-3

14. Pan D, Fan Q, Li P, Liu S, Wu W (2011) Sorption of Th(IV) on Na-bentonite: effects of $\mathrm{pH}$, ionic strength, humic substances and temperature. Chem Eng J 172:898-905. https://doi. org/10.1016/j.cej.2011.06.080

15. Hongxia Z, Xiaoyun W, Honghong L, Tianshe T, Wangsuo W (2016) Adsorption behavior of Th(IV) onto Illite: effect of contact time, $\mathrm{pH}$ value, ionic strength, humic acid and temp. Appl Clay Sci 127:35-43. https://doi.org/10.1016/j.clay.2016.03.038

16. Yin Z, Pan D, Liu P, Wu H, Li Z, Wu W (2018) Sorption behavior of Th(IV) onto activated bentonite. J Radioanal Nucl Chem 316:301-312. https://doi.org/10.1007/s10967-018-5716-5

Publisher's Note Springer Nature remains neutral with regard to jurisdictional claims in published maps and institutional affiliations. 